\title{
RESUMO
}

Vivemos em um mundo contemporâneo e globalizado, envolvendo diversos tipos de sociedade, cultura e sistemas sociais e políticos. Entre tais um dos mais importantes seria a economia que rege as ligações e trocas de mercadoria em todo o mundo, onde há uma alteração constante nesse sistema, variando de cultura e forma de viver. Outro sistema que está em nosso dia a dia e devemos abordar com maior intensidade é o Direito, onde também se faz presente em nosso cotidiano.

A economia e o direito se fazem presente e interligados de forma espontânea em nossa sociedade atual, sendo um para o outro imprescindível, pois ambos em harmonia gera uma amenização nos conflitos atuais, o direito atuando aonde deve impor limites a uns e mostrando direitos à outros, em uma sociedade de desigualdades financeiras o fator Direito se faz presente balanceando cada direito e dever; onde as necessidades de cada um são infinitas e os produtos e matérias primas finitas e muitas vezes até escassa.

Tal estudo visa demonstrar em nosso cotidiano o quanto estamos dependentes dos dois sistemas, e o quanto são cruciais para nossa sobrevivência em coletividade, abordar os pros e contras de cada um é uma tarefa encantadora, pois há tantos questionamentos.

Palavras Chaves: Economia. Direito. Sociedade. Matérias Prima. Escassa.

\section{ECONOMIC ANALYSIS OF LAW}

\section{ABSTRACT}

We live in a contemporary, globalized world, involving different types of society, culture and social and political systems. Among these the most important was the economy that governs the links and exchanges of merchandise around the world, where there is a constant change in the system, ranging from culture and way of living. Another system that is in our daily lives and we need to address with greater intensity is the law, which is also present in our daily lives.

The economy and the right make up present and interconnected spontaneously in our current society, being essential for the other, because both in harmony generates an easing in current conflicts, the right acting where each should impose limits on the rights and the other showing in a society of financial inequalities the law balancing factor is present every right and duty; where the needs of each are infinite and the finite products and raw materials and often even scarce.

This study aims to demonstrate in our daily lives how much we are dependent on the two systems, and how are crucial to our survival in the community, addressing the pros and cons of each is a delightful task as there are so many questions

Keywords: Economics. Key Words. Right. Society. Raw Materials. Scarce. 


\section{INTRODUÇÃO}

O Direito e a Economia são sistemas interligados que, visam solucionar conflitos existentes na sociedade, criados justamente, desde que convivemos em sociedade, seus estudos aprofundados em relação aos dois sistemas começaram no século XVIII. Neles encontramos diferentes métodos para buscar a forma mais justa possível de soluções nos litígios.

A economia é uma atividade que visa a produção, distribuição e consumo de bens e serviços necessários à sobrevivência e a qualidade de vida, sendo necessário para podermos administrar matérias primas escassas e cruciais ao ser humano.

Já o Direito é posto como um sistema que trabalha em prol de pessoas que almejam a justiça como forma de igualar a sociedade. Entretanto a sociedade se desenvolve e se modifica de uma forma muito rápida, necessitando que ambos os sistemas acompanhem tal avanço, muitas vezes a sociedade vivencia conflitos sequentes, necessitando de uma alteração em algum campo muitas vezes é no direito que precisa de uma mudança, através de uma lei, criada justamente por uma causa social.

Da mesma forma acontece com a economia, regra de certa forma a vida das pessoas, impostos, taxas, produtos, salários, na maioria das vezes tais regramentos devem se converter em lei para que se possa progredir economicamente o país, sendo assim, tanto o direito como a economia precisam um do outro, até mesmo para criar uma sociedade mais igualitária.

\section{METODOLOGIA}

Baseado em pesquisa quantitativa e qualitativa, buscando interligar as duas formas para chegar em um consenso. A analise recai sobre as diversas classes sociais, observando sempre o consumo e a demanda pelo judiciário e causas que envolvam valores monetários. Pesquisas em sites com artigos envolvendo o tema abordado, comprovado por números em processos e também a valorização da economia ao passar do tempo.

Desse modo começa a se pensar aonde esta o erro, e porque ambos os sistemas não se interagem como deveria, e como os tribunais estão cada vez mais abarrocados de processos. A desvalorização da moeda e o avanço da economia e não do direito.

Nossos objetos principais é o judiciário a economia e a sociedade brasileira e seus maiores problemas atualmente. 


\section{ECONOMIA E O DIREITO}

O Direito é posto como conjunto de normas para regular as relações sociais e a Economia, conjunto de aplicações matemáticas, onde que tudo se resolve pela -análise técnica ou exata.

A análise do direito numa visão econômica possibilita sua análise de forma mais interessante, pois grande parte dos litígios, dependerão das leis ora aplicadas ao fato concreto. Por outro lado a economia também estabelece normas e os princípios a serem amplamente observados, pois se estabelecerão o custo e benefícios em uma determinada ação.

Estudos mostram que cada sociedade reage de forma diferente ao desenvolvimento econômico numa determinada ação, mas vale ressaltar com cuidado que a análise econômica do direito proporciona um modelo analítico unificado para explicar uma formação, não obstante que normas jurídicas que parecem não ter conexão entre si; é premissa fundamental do modelo: que os indivíduos são agentes racionais que escolhem suas ações para maximizar suas utilidades individuais com base numa visão coerente de preferências transitivas; o modelo também assume que existe uma noção básica de eficiência consistente e inteligível que pode servir de base para as decisões jurídica.

A Economia centra-se na análise da alocação de recursos e no emprego destes de modo mais eficiente para os indivíduos, para as empresas e à sociedade (STIGLITZ; WALSH, 2003, p. 08).

O Direito resolve conflitos e nesta situação, sempre uma pessoa ficará insatisfeita, tendo sido perdedora e a outra ficará contente, ora se ganhar a questão de forma que se questionara.

\section{AS FERRAMENTAS DA ECONOMIA E SUA APLICAÇÃO AO DIREITO}

O presente artigo se pretende estudar a Teoria Econômica Positiva. Neste caso, a economia, vista pelo lado dos economistas, eles "veem as leis como uma 'gigantesca máquina de preços - as leis atuam como preços e impostos que geram incentivos". (VELANOVSKI, 1994, p. 23).

A economia positiva (abordada por Veljanovski, 1994) faz uma abordagem científica através do modelo econômico que por sua vez, se baseia em princípios e que recebe críticas de vários estudiosos na área do direito.

A economia positiva é o ramo da economia que se preocupa com a descrição e explicação dos fenômenos econômicos (Wong, 1987, p. 920). Ela foca nos fatos observáveis e nas relações de causa e efeito e inclui o desenvolvimento e teste de teorias econômicas. 
Quanto mais se visar o lucro mais se terá que observar os bens disponíveis para a sociedade, onde que, sendo os bens econômicos escassos, quando sua capacidade seja sempre inferior ao anseio do litigante.

Os homens não poderão usufruir tudo o que desejam e o processo de escolha, implica renúncias e escolhas.

Veljanoski explica que "A economia se baseia na premissa de que as pessoas, na média, se comportam de forma racional e de acordo com seus próprios interesses" (1994, p. 46).

\section{LEGISLADOR, ECONOMIA E O DIREITO}

O legislador quando da elaboração das leis, pode possibilitar que questões econômicas sejam observadas, com o intuito de fazer o bem necessário e justo aplicado ao direito. Um exemplo deste seria, portanto, quando uma pessoa em uma questão trabalhista, busca todos os meios de se extrair a dívida do empregador, até última instância, e, neste se pergunta: Esta possibilidade atrasa o processo, já que ele mesmo antes de se chegar ao rol de normas positivas, passam antes pela análise do legislador (atribuindo-lhe uma visão técnica sobre a lei), para então ser publicada e sancionada?

\section{DIREITO E SOCIEDADE}

Necessitamos de um Estado para manter a organização da sociedade, este por vez necessita de uma norma cogente para reger nosso cotidiano, tais precisam assegurar direitos essenciais à vida, liberdade individual, enfim direitos garantidos pela Constituição Federal.

Sempre que há conflitos na sociedade, representa que há algo de errado, nesse momento que se faz presente o papel do Estado, trazer a harmonia entre todos os sistemas que envolvem a sociedade, o politico, econômico, social, direito entre os vários que estamos ligados.

Uma norma legislativa traz influencia em todos os campos de uma sociedade, desde as camadas sociais, até mesmo o âmbito politico, econômico; a elaboração de uma norma deve ser muito planejada e visar às consequências de uma norma mal elaborada que muitas vezes ao invés de obter a harmonia da sociedade, pode trazer desvantagens e prejuízos a alguma classe.

Praticamente todas as vezes que se cria uma nova lei, há sempre reflexos em outros sistemas, sempre se alterando de algum modo algum item, refletindo assim na vida das pessoas. Muitas vezes uma norma mal elaborada pode levar a instigação do seu não cumprimento por não atender as necessidades reais de determinado grupo econômico, um exemplo bem claro disso se 
encontra em uma lei que impõe o recolhimento de impostos elevados, onde muitas vezes leva a sonegação.

\section{JUDICIÁRIO E SISTEMA ECONÔMICO}

Vivenciamos uma fase em que o poder judiciário encontra-se abarrotado de ações a serem julgadas. Prejudicando o espaço físico e a saúde dos funcionários; chegando em média quase 4 mil processos por Vara, gerando um cáos não só interno nos órgãos, mas para a população principalmente.

A justiça se faz lenta, e com resultados demorados, desse modo podemos encontrar causas de todos os tipos e assuntos, desde uma causa que poderia ser barrada, através de soluções extrajudiciais, como a conciliação, mediação ou arbitragem, podendo ser evitado que processos simples ficassem anos sem uma solução.

Outro aspecto que envolve judiciário é em relação às custas processuais, são caras, sendo necessário para maioria da população de baixa renda o uso de justiça gratuita. A maioria da classe baixa e sem a devida instrução na maior parte dos casos nem buscam fazer valer seu direito, deixam de entrar com uma ação, pois sabem tanto da demora e que não iriam chegar a lugar nenhum com tal processo. Será que o verdadeiro significado do direito, em busca da justiça, estaria sendo posto em prática realmente no Brasil? O valor da ação se perde com o tempo, e muitas vezes pela demora e por saber que até a conclusão e recebimento de seus débitos seu dinheiro estaria totalmente desvalorizado.

A economia muda, assim como o direito, mas pelo fato do judiciário encontrar-se em um momento de muita demanda, o direito não acompanharia a economia, pois o ciclo de dinheiro e investimento pelo governo não pode parar, visando o crescimento econômico do país, a economia se transforma constantemente, impostos, salários, alimentos e até mesmo o custo de vida ao passar do tempo aumenta.

A desvalorização da moeda nacional é por consequência um dos maiores motivos do desanimo frente às ações que hoje valeria muito poder monetário, até seu encerramento não pagaria todo o trabalho do advogado.

Outro aspecto importante em relação ao tramite de um processo está relacionado ao valor da causa, e às custas processuais. No mínimo o tempo de duração de um processo deve ser proporcional ao seu valor, visando justiça efetiva para os cidadãos. Em outros casos não se compensa em relação ao longo prazo que um processo dura, em média anos, chegando ao final do processo o valor da causa já estará desvalorizado, é de se pensar em relação ao assunto, pois 
muitos casos com valor baixo além de estar amontoando os tribunais dificultam o julgamento eficaz dos mesmos.

Muitas vezes uma norma econômica visa sim o crescimento de uma classe social que já está estabilizada e procura crescer mais, enquanto para de renda inferior além do capitalismo procurar dificultar a situação financeira, impede de um cidadão criar estímulos para acionar a justiça ao seu favor justamente por se sentir esmagado por normas que acabam privando de buscar o mais importante o egresso em busca de justiça.

\section{RESULTADOS}

Obtivemos um resultado unanime em relação a problematização, onde é possível identificar que o acesso ao judiciário em busca de soluções envolvendo ações de indenização é cada vez mais acentuado. Outro ponto que se observa é que o investimento na economia e muito maior do que na área do judiciário, onde há um desenvolvimento desigual nas camadas da população e um maior acesso pela população sem problemas monetários. A economia avança mais rápido do que as leis.

\section{DISCUSSÕES}

O acesso cada vez mais maior no judiciário se da pelo fato de um aumento na desigualdade entre classes sociais, possibilitando uma maior dificuldade em solucionar os mesmo, onde a desvalorização de cada causa só aumenta decorrente de uma falta de avanço no que tange a criação de leis que acompanhe tanto a economia social como o crescimento e problematizações.

Cada vez mais se aumenta os impostos, tarifas, o preço dos produtos e um menos acesso a tais necessidades, uma delas seria ao judiciário que a maioria da população de renda baixa não consegue ver confiança em um ordenamento sem solução. Desse modo o legislador deve se atentar mais ao teor e influencias de uma nova lei na sociedade.

A solução seria dessa forma um maior equilíbrio na distribuição de investimentos e imposição de impostos.

\section{CONCLUSÃO}

O presente estudo demonstra o quanto é importante à economia em uma sociedade, as regras econômicas são necessárias para se transformar todos os campos de uma sociedade, jamais imaginaríamos que a mesma seria importante para às custas de um processo, pois bem, se 
encontra presente e muito no judiciário, custas elevadas e vara lotadas de processos nos mostra que precisamos de uma mudança urgente quanto a forma de tratamento de certos problemas.

Estamos adentrando a fase da informatização dos processos, uma forma que pode dar certo quanto a agilidade dos processos, outro aspecto que deve ser analisado se situa em relação às pequenas causas que já poderia ter acesso amplo á órgãos extrajudiciais, que além de ser mais ágil, poderia compensar tanto em relação ao valor das custas que seriam praticamente nulo, e o valor de acordo entre as partes.

Para o crescimento de um país os direitos em geral devem acompanhar as leis econômicas para que possam caminhar juntos, pois em um país que a economia é mais avançada que os direitos da maioria dos cidadãos não poderá haver igualdade e progresso.

A partir do momento que um direito fundamental ser base de uma norma econômica, viabilizando o acesso de todos à justiça, poderá se pensar em desenvolvimento econômico de fato.

\section{REFERÊNCIAS}

AGUILLAR, Fernadno Heren. Direito Econômico: do direito nacional ao direito supranacional. São Paulo: Atlas, 2006.

ALVAREZ, Alejandro Bugalho. Análise Econômica do Direito: contribuições e desmistificações. Direito, Estado e Sociedade - v. 9, n.29, jul./dez. 2006. p. 49-68. Disponível em: http://www.estig.ipbeja.pt/ ac direito/Bugallo n29.pdf. Acesso em: 28 abr. 2014.

STIGLITZ; WALSH, 2003, p. 08 . Disponível em http://www.ambitojuridico.com.br/site/index.php/?n_link=revista_artigos_leitura\&artigo_id=12533\&revista_caderno $=27$. Acesso em 28 abr. 2014.

VELJANOVSKI, Centro. A economia do direito e da lei: uma introdução. Trad. De Francisco J. Beralli. Rio de Janeiro, IL, 1994.

Análise econômica do direito" Cooter, Robert; Ulen, Thomas. (2010). Direito \& Economia, 5a edição. Porto Alegre: Bookman.

WORLD BANK DOCUMENT. Brazil, Judicial performance and private sectors impacts: findings from World Bank sponsored research. Report 26261- BR. July, 1, 2003.

ZYLBERSZTAJN, Decio; Sztajn, Rachel. (2005). Direito \& Economia: Análise Econômica do Direito e das Organizações. Rio de Janeiro: Elsevier. 